\title{
Mulheres (in)Subordinadas: o Empoderamento Feminino e suas Repercussões nas Ocorrências de Violência Conjugal ${ }^{1}$
}

\author{
Mirian Béccheri Cortez \\ Lídio de Souza \\ Universidade Federal do Espírito Santo
}

\begin{abstract}
RESUMO - Neste trabalho, explora-se o modo como a compreensão e o desempenho dos papéis de gênero se relacionam às ocorrências de violência (física, psicológica e sexual) dos maridos contra as esposas. Quatro mulheres que apresentaram queixa na Delegacia de Defesa da Mulher contra as agressões físicas perpetradas por seus parceiros e que conviviam com eles foram entrevistadas utilizando-se um roteiro de entrevista, que recolheu dados pessoais e informações a respeito das concepções sobre homem, mulher e relacionamento conjugal/afetivo. As entrevistas foram processadas pelo software Alceste, sendo a Análise de Conteúdo utilizada para complementar a análise. Os dados revelam a coexistência de concepções tradicionais de gênero com ações de insubordinação dessas mulheres (trabalho assalariado, amizades, questionamento da vida sexual). Esses aspectos, sinalizadores do empoderamento das mulheres, relacionam-se à agressividade dos parceiros que, excluídos dos debates feministas e buscando proteger sua masculinidade, usam a violência para suprimir as manifestações femininas de poder.
\end{abstract}

Palavras-chave: violência conjugal; esposas; empoderamento feminino.

\section{(In)Subordinated Women: Feminine Empowerment and its Repercussions on Marital Violence Occurrences}

\begin{abstract}
On this article, the effects of gendering conception and gender roles practices on violence (physical, psychological and sexual) against spouses are explored. Four women that had registered declaration of suffering physical abuse from their partners and that still live with them were interview based on a script with search for personal data and information about marital relationship, men and women conceptions. Interviews were submitted to Alceste software, that was the Content Analysis used as a complementary method analysis. Data show that gendering traditional conceptions and insubordination acts share places (such as paid work, friendships, and judgments about sexual life). These aspects, signal of women empowerment, are related to partners' aggressiveness, which were excluded of feminist debates and are trying to protect their masculinity by using violence to suppress feminine manifestations of power.
\end{abstract}

Key words: marital violence; spouses; feminine empowerment.

Este artigo apresenta parte dos dados obtidos em uma pesquisa desenvolvida com casais envolvidos em violência conjugal. Busca-se, aqui, clarificar alguns aspectos relativos à percepção de relacionamento conjugal/afetivo e de papéis masculinos e femininos entre mulheres vítimas de violência de seus parceiros. Dentre os autores e autoras que discutem o tema da violência conjugal, uma definição de violência bastante aceita e utilizada é a fornecida por Chauí (1999), que a compreende como conversão da diferença numa relação de desigualdade, e que objetiva a dominação, a exploração e a opressão do outro, por meio de sua coisificação. Complementando essa definição, Saffioti (1999) acrescenta que violência é todo agenciamento capaz de violar os Direitos Humanos.

No presente trabalho, para nos referirmos à violência praticada pelo homem contra sua parceira íntima (namorada, amante, esposa), utilizaremos as expressões violência conjugal (masculina) e violência contra a mulher, pois mesmo

1 Apoio Financeiro: Capes.

2 Endereço: Programa de Pós-Graduação em Psicologia, Centro de Ciências Humanas e Naturais, Universidade Federal do Espírito Santo, Avenida Fernando Ferrari, 514, Goiabeiras, Vitória, ES, Brasil 29075910.E-mail: mibecz@yahoo.com.br reconhecendo outras expressões utilizadas para esse fim (violência doméstica ou de gênero, por exemplo), acreditamos que nossa opção especifica com mais clareza os atores e os contextos por nós explorados. Entre as argumentações que tentam explicar, ou ainda, "justificar" a violência que se faz presente nos relacionamentos, identificamos explicações externas (aceitação pela sociedade, consumo de álcool ou drogas ilícitas pelo homem, dificuldades financeiras) e internas (personalidade do agressor, ciúme, histórico familiar, padrão cultural aprendido/reproduzido) (Cortez, Padovani \& Williams, 2005; Pondaag, 2003; Soares, 1999), as quais, em geral, tendem a reafirmar a "potencialidade natural" do homem à agressividade e da mulher à docilidade.

Ao fazer uma análise sobre perpetuação e profusão da violência, Marcondes Filho (2001) afirmou que quando os atos de violência são justificados por um benefício maior, a violência naturaliza-se, torna-se "normal". A naturalização dos papéis masculinos e femininos está intimamente relacionada às concepções tradicionais, e ainda atuais, de gênero. Compreendido como uma categoria de análise (como etnia e classe), o gênero é um componente ativo das práticas sociais e, na nossa sociedade, implica na hierarquização entre os 
sexos, ou seja, no estabelecimento de um lado com poder (homem forte, racional, ativo) e de outro sem ou com o mínimo desse (mulher sensível, emotiva, passiva). Tal dicotomia é descrita por diversos autores, entre os quais Araújo (2005), Bourdieu (2003), Giffin (1994) e Torrão Filho (2005).

Apesar de ser um aspecto marcante em nossa cultura, essa dicotomia rígida vem sofrendo, ao longo dos anos, uma série de abalos, decorrentes principalmente dos avanços das conquistas femininas relativas à inserção da mulher em espaços considerados "masculinos". Essas conquistas permitem à mulher, categoria submetida a processos de exclusão pelo grupo dominante masculino, ferramentas para se empoderarem e conseguirem lutar por maior autonomia. Ressalta-se aqui o conceito de empoderamento feminino (empowerment), que deve ser compreendido, como bem descreve Léon (2001), como abarcando duas dimensões: uma coletiva e outra individual. O empoderamento implica, pois, no reconhecimento das restrições sociais a que a categoria está submetida e da necessidade de reversão dessa situação, por meio de mudanças em um contexto amplo/público (inserção em cargos de poder/decisão, educação não sexista e serviços de saúde adequados) e também em contextos mais específicos, ou individuais (aumento de auto-estima e autonomia, reorganização do trabalho doméstico, etc).

Reconhecendo que as definições e prescrições de masculino e feminino são desenvolvidas simultaneamente e de modo a estabelecer pólos opostos para os dois gêneros (forte/fraco; ativo/passivo), é possível relacionar o empoderamento das mulheres e a crise da masculinidade, essa última descrita por Nolasco (1997). Se o "homem de verdade" é aquele que possui a maior quantidade de características relacionadas à masculinidade hegemônica (Connell, 1995, 2005), de que modo esse homem reage ao ver seu espaço e direitos serem também utilizados, e aparentemente ameaçados, por mulheres? Em sua pesquisa com 22 agressores conjugais, Wood (2004) encontrou informações que apontam que a ocorrência de violência contra a parceira é um meio de controlá-la, de modo que o agressor mantenha sua masculinidade intacta. Nesses termos, entre os dados descritos pela autora, podemos destacar as justificativas para as agressões, divididas em quatro subtemas: a) ela me desrespeitou como homem, b) ela me provocou, c) o homem tem o direito de controlar sua mulher e d) a mulher aceita a situação de violência. Como ressaltou Wood, todos os entrevistados apresentaram uma visão patriarcal de masculinidade, na qual os homens devem estar no comando dos relacionamentos e, se neces- sário, utilizar violência para controlar e "educar" a parceira, mostrando a ela "seu devido lugar" e a posição de cada um no relacionamento.

Segundo Saffioti (2002, p. 198), a violência contra a mulher ocorre porque a "ideologia de gênero é insuficiente para garantir a obediência das vítimas potenciais do ditame do patriarca". Apesar disso, e considerando ainda a força de concepções tradicionais de gênero, temos publicações que indicam que casais envolvidos em relacionamentos violentos buscam manter as expectativas (externas e deles próprios) relacionadas à constituição e manutenção do lar e aos papéis que entendem dever ser cumpridos pela mulher, como mãe e esposa, e pelo homem, como pai e marido. Miller (2002, p. 251) descreveu que "a expectativa geral é de que as mulheres apóiem a 'reputação' da família, com suas atitudes sociais tradicionais, e mantenham os 'problemas familiares' dentro do próprio lar". Diversos autores (entre eles, Anderson \& Umberson, 2001; Gilbert, 2002; Greig, Kimmel \& Lang, 2000; Jenkins \& Aubé, 2002) relacionam a tendência dos homens a agredir suas parceiras e as concepções tradicionais de gênero e ressaltam a importância de se investigar essas compreensões entre homens e mulheres para a predição de comportamentos violentos. Nesse sentido, interrogamos se em um relacionamento amoroso as diferenças nas concepções de gênero podem ser relacionadas aos desentendimentos e agressões físicas, psicológicas ou sexuais.

Nesta investigação, procuramos verificar, por meio de entrevistas com mulheres em situação de violência, como concepções e práticas de gênero presentes em relacionamentos violentos contribuem para a produção de conflitos que resultam em violência física, psicológica ou sexual do marido contra sua companheira.

\section{Método}

\section{Participantes}

Participaram da pesquisa quatro mulheres, com histórico de violência conjugal em seus relacionamentos atuais e que haviam registrado na Delegacia de Defesa da Mulher (DDM) queixa contra seus parceiros por agredi-las fisicamente. $\mathrm{Na}$ Tabela 1, constam alguns dados sobre as entrevistadas (nomes fictícios).

As quatro participantes viviam consensualmente com seus maridos. Mara havia deixado de morar com seu parceiro após a última briga, mas mantinha contato diário com ele.

Tabela 1. Informações sobre as mulheres entrevistadas.

\begin{tabular}{|c|c|c|c|c|c|c|}
\hline Participante & Idade & Tempo de relacionamento & Idade dos filhos & Escolaridade & Profissão & $\begin{array}{c}\text { Início das agressões } \\
\text { físicas }\end{array}$ \\
\hline Amanda & 31 & 13 anos e 3 meses & $\begin{array}{l}14 ; 11 \\
9 \text { e } 5\end{array}$ & $\begin{array}{l}\text { fundamental } \\
\text { incompleto }\end{array}$ & $\begin{array}{c}\text { auxiliar } \\
\text { serviços } \\
\text { gerais }\end{array}$ & durante o namoro \\
\hline Fabiana & 32 & 15 anos & $15 ; 7$ e 10 & $\begin{array}{l}\text { fundamental } \\
\text { incompleto }\end{array}$ & manicura & há 12 anos \\
\hline Carina & 42 & 23 anos & 15 e 20 & $\begin{array}{l}\text { fundamental } \\
\text { incompleto }\end{array}$ & diarista & há 17 anos \\
\hline Mara & 25 & 4 anos & 5 & $\begin{array}{l}\text { magistério } \\
\text { completo }\end{array}$ & professora & durante o namoro \\
\hline
\end{tabular}


Amanda, Fabiana e Mara possuem um filho de um relacionamento anterior. Três das esposas não completaram o ensino fundamental e Mara concluiu o magistério. Todas exerciam atividade remunerada no período em que a entrevista foi realizada, recebendo, em média, um salário mínimo mensal (na época $\mathrm{R} \$ 300,00$ ).

\section{Contato com as participantes}

As participantes foram contatadas em duas situações: após as audiências de conciliação nos Juizados Especiais Criminais (Jecrins) e no início das sessões de grupo com casais, desenvolvidas pelo Núcleo de Apoio Psicossocial aos Apenados (NAPA). Ao contatar as possíveis participantes, a pesquisadora se apresentava como aluna de pós-graduação, informando que procurava voluntários para uma pesquisa sobre relacionamentos violentos, sem vínculos com a instituição em que o casal estava sendo contatado ou com outras instituições ligadas a órgãos de justiça. Às interessadas eram requisitados números de telefone para contato posterior e agendamento da entrevista.

\section{Instrumento e coleta dos dados}

Utilizou-se para a coleta um roteiro com duas partes: a primeira recolheu informações pessoais e sócio-demográficas de cada participante (idade, escolaridade, profissão, salário) e informações sobre o relacionamento do casal (duração, início das agressões). A segunda parte do roteiro investigou as concepções acerca dos papéis de gênero do homem e da mulher dentro do ambiente familiar e conjugal, descrições de episódios de agressão física e as percepções das entrevistadas sobre si mesmas, seus parceiros e relacionamentos. As entrevistas foram gravadas, com a anuência das participantes. O Termo de Consentimento Informado (TCI) foi lido na presença das entrevistadas, sendo quaisquer dúvidas esclarecidas antes da sua assinatura em duas vias. As esposas foram entrevistadas individualmente pela autora ou por uma aluna-estagiária de graduação, devidamente orientada para isso, nos locais de preferência das participantes: em suas próprias residências ou em sala cedida pelo NAPA. As entrevistadas no NAPA receberam passes de ônibus.

\section{Tratamento dos dados}

As informações coletadas na primeira parte do roteiro de entrevistas foram utilizadas para caracterizar brevemente as participantes. Os dados da segunda parte do roteiro foram transcritos integralmente e submetidos aos seguintes procedimentos:

\section{Alceste (Analyse Lexicale par Contexte d'um Ensemble de Segments de Texte)}

Esse software tem como função apreender informações essenciais contidas em um conjunto de textos, como entrevistas, artigos ou ensaios literários. As unidades básicas de análise com que trabalha são: a) Unidades de Contexto Inicial (UCI): determinadas pelo pesquisador e pela natureza de sua pesquisa, são divisões primárias do grupo de textos analisa- dos. Cada uma das quatro entrevistas foi considerada uma UCI; b) Unidades de Contexto Elementares (UCE): frases dimensionadas pelo programa de acordo com o tamanho do corpus, de sua pontuação e da ordem de aparição no texto (Menandro, 2004; Oliveira, Gomes \& Marques, 2005); e c) Classe/contexto lexical: corresponde a um tema extraído da análise do corpus. O tema é identificado pela análise de UCEs e vocabulários específicos da classe.

Essas classes são construídas pelo programa por meio da Classificação Hierárquica Descendente (CHD), que considera o vocabulário específico das classes (freqüência, porcentagem e força de relação de cada palavra com o contexto em que foi inserida), apresentando-o em um dendrograma (gráfico em forma de árvore), o qual indica o número de classes, suas estruturas e a relação entre elas (proximidade ou oposição). Uma segunda técnica, a Análise Fatorial de Correspondência (AFC), descreve tabelas por meio do cruzamento entre o vocabulário e as classes, possibilitando visualizar, a partir de um plano fatorial, a distribuição e relação entre as classes e seus vocabulários identificados pela CHD (Ribeiro, 2000).

Destacamos que o trabalho do Alceste se revela proveitoso quando em "parceria" com o do pesquisador, uma vez que o primeiro oferece uma "topografia do discurso" (Kalampalikis, citado por Menandro, 2004), ao organizar e destacar conteúdos e temas do corpus, enquanto o segundo irá interpretar e dar significados ao produto gerado pelo software. Desse modo, o procedimento de Análise de Conteúdo (Bardin, 1977/2002), foi utilizado para complementar as temáticas propostas pelo Alceste.

\section{Análise de conteúdo}

A Análise de Conteúdo é um recurso metodológico que "articula a superfície descrita e analisada com os fatores que determinam suas características: variáveis psicossociais, contexto cultural, contexto e processo de produção da mensagem" (Minayo, 1993, p. 203). Utilizou-se, no presente trabalho, a técnica da análise categorial, que busca identificar e analisar os "núcleos de sentido", ou temas, que compõem o texto. Estes são entendidos como "unidades de significação" encontradas no texto analisado durante as leituras guiadas por uma teoria específica (Bardin, 1977/2002).

\section{Conjugação dos procedimentos de análise}

A análise obedeceu à seguinte ordem: a) Análise da CHD; b) Acréscimo, nas classes definidas pela CHD, de temas complementares identificados pela Análise de Conteúdo; e c) Análise da AFC.

\section{Resultados}

\section{Classificação hierárquica descendente e análise de conteúdo}

A CHD realizada pelo Alceste subdividiu o corpus em 493 UCEs, das quais $428(86,82 \%)$ foram consideradas relevantes e analisadas pelo programa, demonstrando boa consistência do conteúdo analisado. Foram identificados dois eixos: o primeiro compreende a classe 1, com 281 das 
UCEs (65,65\% dos dados analisados) e o segundo eixo corresponde ao subagrupamento das classes 2 e 3 , contendo as demais UCEs analisadas (34,35\%). A Figura 1 contém o dendrograma gerado pelo programa, já com as classes e eixos nomeados, os índices de proximidade $(r)$, que sinalizam a força da relação existente entre as classes, e os valores de qui-quadrado $\left(X^{2}\right)$ de cada uma. Esses últimos indicam a relevância semântica da palavra dentro de cada classe. Ressaltamos que, como afirma Menandro (2004), índices de proximidade superiores a 0,5 indicam relações mais significativas entre as classes e entre os eixos, enquanto índices baixos podem ser indicativos de oposição entre esses. Observa-se, na Figura 1, a presença de radicais acrescidos do símbolo (+), o que significa que variações de uma mesma palavra foram identificadas e analisadas. No relatório gerado pelo Alceste, há uma seção que especifica as palavras a que a raiz identificada se refere e a quantidade que cada uma delas apareceu na classe, que aparece entre parênteses. Exemplos: responsabilidade+: responsabilidade (15), responsabilidades (1); carinh+: carinho (23), carinhosa (9), carinhoso (18); beb+: bêbado (2), bebe (5), bebem (1), beber (5), bebia (1); machuc+ : machucado (2), machucou (4).

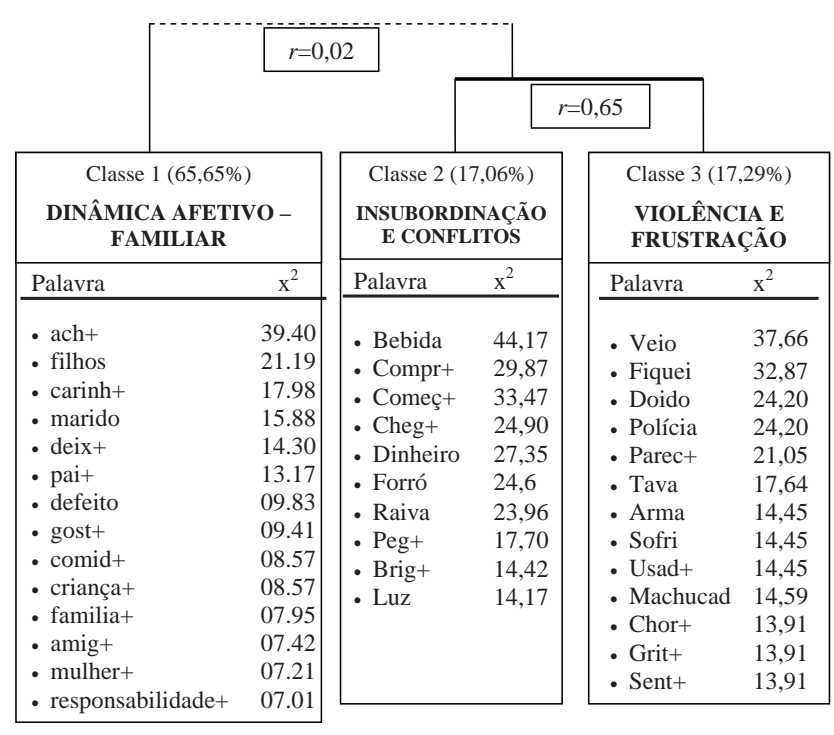

DINÂMICA DA VIOLÊNCIA

Figura 1. Dendrograma do conteúdo das entrevistas com as mulheres.

O primeiro eixo, constituído pela classe 1, foi denominado Dinâmica Afetivo-Familiar e é composto por elementos-base para a boa relação afetiva, principalmente do casal, bem como do bom funcionamento do lar e da família. Com relação à dinâmica afetiva, são recorrentes no corpus analisado a necessidade de companheirismo, diálogo e demonstrações de carinho, como mostram os seguintes recortes de UCEs (o símbolo \#, inserido pelo Alceste, indica as palavras mais fortemente relacionadas à classe): Um \#bom_marido é um \#marido \#companheiro, \#amigo. É \#pai, é irmão. Eu \#acho que um \#marido tem que ser tudo na \#vida \#da \#mulher, como a \#mulher tem que ser pra ele.

Quanto à dinâmica familiar, prevalecem as descrições de papéis tradicionais masculinos e femininos (homem/provedor; mulher/cuidadora) e a necessidade da execução adequada das funções (direitos e obrigações) de cada um dos cônjuges como marido, pai (não \#deixa \#faltar \#as coisas, então ele tem essa muito \#boa \#qualidade, que eu \#acho isso muito \#importante. \#cuida \#das \#crianças, paga \#as contas em dia, não \#deixa atrasar nada) e como mãe e esposa: "Enquanto mãe, eu deixo de comer pra dar pros meus filhos comer, (...). Eu cuido das roupas deles, da comida..." (Fabiana). O \#direito dele é assim, chegar em casa e ter \#comida \#pronta, ter a \#roupinha dele dobradinha. Ter \#café. \#deixa eu ver mais, ter a \#roupa dele toda \#arrumadinha. Interessante notar como o tradicionalismo dos papéis, já naturalizados, repercute no modo como as entrevistadas qualificam o cuidado com a casa: um dever para elas e um direito para seus maridos.

Nessa mesma classe, encontramos percepções estereotipadas sobre os homens, as quais tendem a naturalizar os defeitos identificados nos maridos: "Trair todo homem trai (...) quem me dera se ao invés de me bater ele me traísse (...) Tem muito homem que prefere a cervejada, o futebol e os amigos e deixa a mulher sozinha em casa" (Mara). Algumas características da mulher "ideal" são descritas, delineandose a mulher como portadora de uma índole mais delicada e sensível, mesmo quando a entrevistada não se identifica, de fato, com tais expectativas: [eu devia] concordar mais com \#as coisas. Eu \#quero que tudo \#seja \#do meu \#jeito. Tudo que eu \#quero, eu \#acho muito isso, eu \#acho que me identifico [com uma boa mulher] na \#parte de ser \#carinhosa, de ser \#dedicada com o lar, de \#cuidar \#das coisas certinho, \#do \#marido, \#da \#roupa \#das \#crianças. Outro exemplo: “ $a$ partir do momento que ela tem família, casou (...) ela tem que saber dos seus limites. (...) a não ser que tem roupa que a mulher veste e o homem não gosta, mas ela acha que a roupa tá bem nela e que é implicância dele” (Fabiana).

Além de seus papéis domésticos tradicionais, todas as esposas exercem trabalho remunerado fora de casa, o que se deveu principalmente à necessidade de contribuir com o aumento da renda familiar ou, ainda, como o único meio de viabilizá-la. Apesar da presença de alguns elementos não-habituais, compreende-se que, idealmente, para as participantes, os padrões tradicionais de gênero guiam a compreensão do que é um bom funcionamento das dinâmicas familiares e afetivas.

O segundo eixo, denominado Dinâmica da Violência, reúne as classes 2 e 3 , fortemente relacionadas $(r=0,65)$. Esse eixo contém exemplos de episódios do dia a dia das entrevistadas, em especial aqueles ligados às brigas do casal. Notamos que entre os dois eixos delimitados pelo Alceste, o índice de proximidade é praticamente nulo $(r=0,02)$, o que indica o caráter de oposição/“cisão" entre duas visões divergentes de relacionamento: de um lado, as idealizações sobre família e a relação conjugal e, do outro, elementos mais próximos do cotidiano violento das entrevistadas.

A classe 2, Insubordinação e Conflitos, agrupa palavras que caracterizam comportamentos masculinos considerados prejudiciais para o convívio conjugal e familiar, como agressividade, consumo de bebida alcoólica e outras drogas, descumprimento das obrigações de marido (freqüentar "forrós" sozinho, ter casos extra-conjugais) e de chefe de família (deixar de pagar contas e de comprar mantimentos, pouco contato com os filhos). Destacamos dois exemplos: "Se a gente brigasse, ele se arrumava e saía, voltava só de madrugada (...). Vai eu fazer uma coisa dessas, ele vai e me 
metia o cacete. Agora, ele podia, se arrumava, pegava o carro e rachava fora, voltava bêbado, é muita humilhação" (Mara); destacou o papel da \#luz e me deu, dobrou e me deu. No outro \#dia cortou minha \#luz. Ele \#pegou e \#gastou o \#dinheiro \#todinho. E eu não olhei aquele \#coisinho que eles \#colocam o, quando eles \#pagam, não registrou. E eu, ele me deu dobrado, eu pus no bolso, \#pra mim estava \#pago.

As esposas reconhecem, assim, que os padrões ideais (descritos na classe 1) não estão presentes em seus relacionamentos. Elas revelam cobrar de seus parceiros atitudes com relação a essas falhas, buscando (nem sempre no momento ou do modo mais adequado) discuti-las e corrigi-las, o que muitas vezes culmina em uma resposta agressiva do marido: "ele não faz nada não. Sou eu que falo. Aí eu começo a discutir porque chegou bebido..." (Carina). Bastante ressaltada nas entrevistas, a violência psicológica por parte do marido se faz presente em ameaças de morte e de punição física, humilhações e ofensas à esposa e familiares: "me xinga de nomes absurdos, fala que eu sou safada, que eu sou piranha" (Amanda); "ele faz é assim 'o dia que eu ficar sabendo que você tá com alguém eu te levo pro mato e te mato'” (Carina).

Importante ressaltar que, nessa classe, estão presentes relatos que revelam que as discussões descritas são desencadeadas por atitudes da mulher que desagradam ao homem como: fazer cobranças quanto à participação do marido na família, ter um emprego assalariado contra a vontade do marido, se arrumar, gostar de se enfeitar, negar-se a manter relações sexuais com o parceiro. Ilustram algumas dessas atitudes os relatos abaixo:

(...) ele é tão grosso, que ele \#fica assim, no \#máximo um \#mês bom. Depois \#começa tudo de novo. Só \#pra pessoa dar um tempo e \#esquecer. É quando eu não quero mais \#aceitar ele [sexualmente] que ele, nossa, mas ele me \#xinga mesmo.

"Ele cortava minhas roupas, entendeu? Ele falava não usa, aí é que eu usava, se falava que não era pra eu usar aí é que eu usava mesmo, entendeu?" (Mara)

Compreendemos, então, que a insubordinação contida nas ações acima descritas e as cobranças quanto ao bom desempenho como chefe da família e provedor podem ser compreendidas como mais um passo no processo de empoderamento dessas mulheres, uma vez que se mostraram determinadas a cumprir suas vontades e enfrentar de alguma maneira a situação de subordinação que seus maridos impõem. A determinação destas mulheres no que concerne à afirmação de seus interesses e direitos culmina com a formalização da denúncia das violências sofridas.

A classe 3, nomeada Violência e Frustração, agrega conteúdos relacionados às descrições de brigas, configurando um quadro geral sobre as brigas com agressões físicas: datas e locais, tipos de agressões físicas e verbais, atitudes adiante da violência do parceiro, sentimentos durante e após a briga, conseqüências das brigas (danos físicos, emocionais e desgaste da relação afetiva). Nos episódios de violência física, as entrevistadas contam que seus parceiros "vão pra cima" delas, investindo chutes, socos e insultos ou, ainda, ameaçando com arma de fogo ou faca. Em alguns relatos temos a descrição de trocas de ofensas entre os parceiros, por meio de gritos, mas não há descrição de agressões físicas das esposas contra os parceiros, apesar dessas poderem ocorrer como tentativas de proteção do próprio corpo ou por iniciativa das próprias mulheres (Alvim \& Souza, 2005; Anderson \& Umberson, 2001; Dutton \& Nicholls, 2005, Dasgupta, 2002; Kelly, 2004).

A maioria das agressões descritas ocorreu dentro da residência, revelando que "a segurança do lar" é também um espaço que delimita simbolicamente o poder de ação sobre a esposa. Segundo as entrevistadas, nas situações de brigas, o parceiro parece "doido" ou "possuído", avaliação que pode se dever à impossibilidade de controle ou negociação com o esposo, tornando ainda mais intensos seus sentimentos de medo e desamparo. As esposas, então, buscam proteção: gritam por ajuda, pedem que a agressão se encerre, choram e buscam se afastar do marido (trancando-se em algum cômodo ou fugindo de casa). Familiares (pais, sogra, filhos mais velhos), um médico, empregadoras/chefes do serviço e mesmo uma desconhecida foram indicados como parte da rede de apoio que as entrevistadas buscaram para conseguir proteção ou desabafar. A procura por pessoas geralmente próximas sugere que a violência sofrida foi considerada uma questão a ser tratada privadamente (Bruschi, de Paula \& Bordin, 2006); decisão aparentemente mediada pela compreensão da missão cultural da mulher de "preservação do lar e da família", juntamente com outro construto tradicional - a privacidade do lar (Miller, 2002). A busca por ajuda legal, iniciada pelo registro de denúncia na DDM, foi pré-requisito para a seleção das mulheres participantes e, em todos os casos, as esposas haviam realizado a denúncia pela primeira vez, apesar de as agressões já ocorrerem há vários anos.

Além dos danos físicos (arranhões, contusões, hematomas, perda de dente), foram reveladas também implicações emocionais que levam as mulheres a avaliar suas posturas e sentimentos em relação ao marido e ao relacionamento. Elas descrevem a quebra das idealizações românticas sobre a relação homem-mulher e o "desencanto" com seus relacionamentos, o que se refletiu também na qualidade do envolvimento sexual, tendo a cama se tornado um "campo de batalha, revelador, em alguns casos, do desprazer cronificado" (Dantas-Berger \& Giffin, 2005, p. 422).

De acordo com Day e cols. (2003), a agressão física perpetrada pelo parceiro íntimo é quase sempre acompanhada de agressões psicológicas e, de um quarto a metade das vezes, também de sexo forçado. Entre as entrevistadas, três relataram o desinteresse pelo contato mais íntimo com o parceiro, decorrente do desgaste do relacionamento e do medo de contrair DSTs, posto que sabiam dos casos extraconjugais de seus maridos "aí eu não sei se ele está na farra com amigo, se está com mulher, né, e aí, assim, ele com a cara cheia de bebida, pega alguma doença dessas mulheres" (Fabiana). Em oposição a esse cuidado com o corpo, encontramos relatos que descrevem a relação sexual como uma obrigação da esposa: “(...) embora eu não esteja com vontade, mas sempre estou ali, disposta a ele" (Amanda); e também para evitar acusações de infidelidade e brigas: "É quando eu não quero mais aceitar ele que ele, nossa, mas ele me xinga mesmo. Fica com raiva. (...), me xinga de piranha, que eu estou com outro homem..." (Carina); descrições também encontradas por Dantas-Berger e Giffin (2005) e Marques (2005). Sobre esse 
tema, temos relatos sobre relações sexuais desprazerosas ou mesmo repugnantes: “(...) acaba de ter relação, e nossa, me dava uma tristeza, um mal-estar, sabe, no corpo. Eu me sentia suja..." (Amanda). Fabiana revelou ter sido abusada sexualmente pelo marido, mas mesmo reconhecendo a violência do ato, não o denunciou: "Eu falava que não queria, (...) ele me segurou e falou que eи era mulher dele”. Para Saffioti e Almeida (2003, p. 87), o dever conjugal, e acrescentamos aqui o medo de retaliações por parte do marido, obriga a mulher a ceder aos seus desejos, mesmo não consentindo na relação sexual, uma vez que “o consentimento só pode estar alicerçado no desejo". E o desejo pelo marido parece ter acabado para essas mulheres.

Essa classe compõe, com a segunda, o eixo denominado Dinâmica da Violência. A relação entre essas duas classes é bastante clara e nos mostra recortes da construção de situações violentas que envolvem agressões psicológicas, físicas e sexuais nos relacionamentos conjugais. Salientamos, por fim, que essa última classe completa "o ciclo de conflitos" que mostra o desenvolvimento do episódio de violência por meio dos desencontros entre o ideal descrito na classe 1 e o convívio real que se apresenta na classe 2 e que se torna ainda mais debilitante (para a mulher e para a própria relação) na classe 3.

\section{Análise fatorial de correspondência (AFC)}

O resultado da AFC realizado pelo Alceste pode ser visualizado na Figura 2. Para facilitar visualização da sua distribuição, as palavras mais fortemente relacionadas a cada

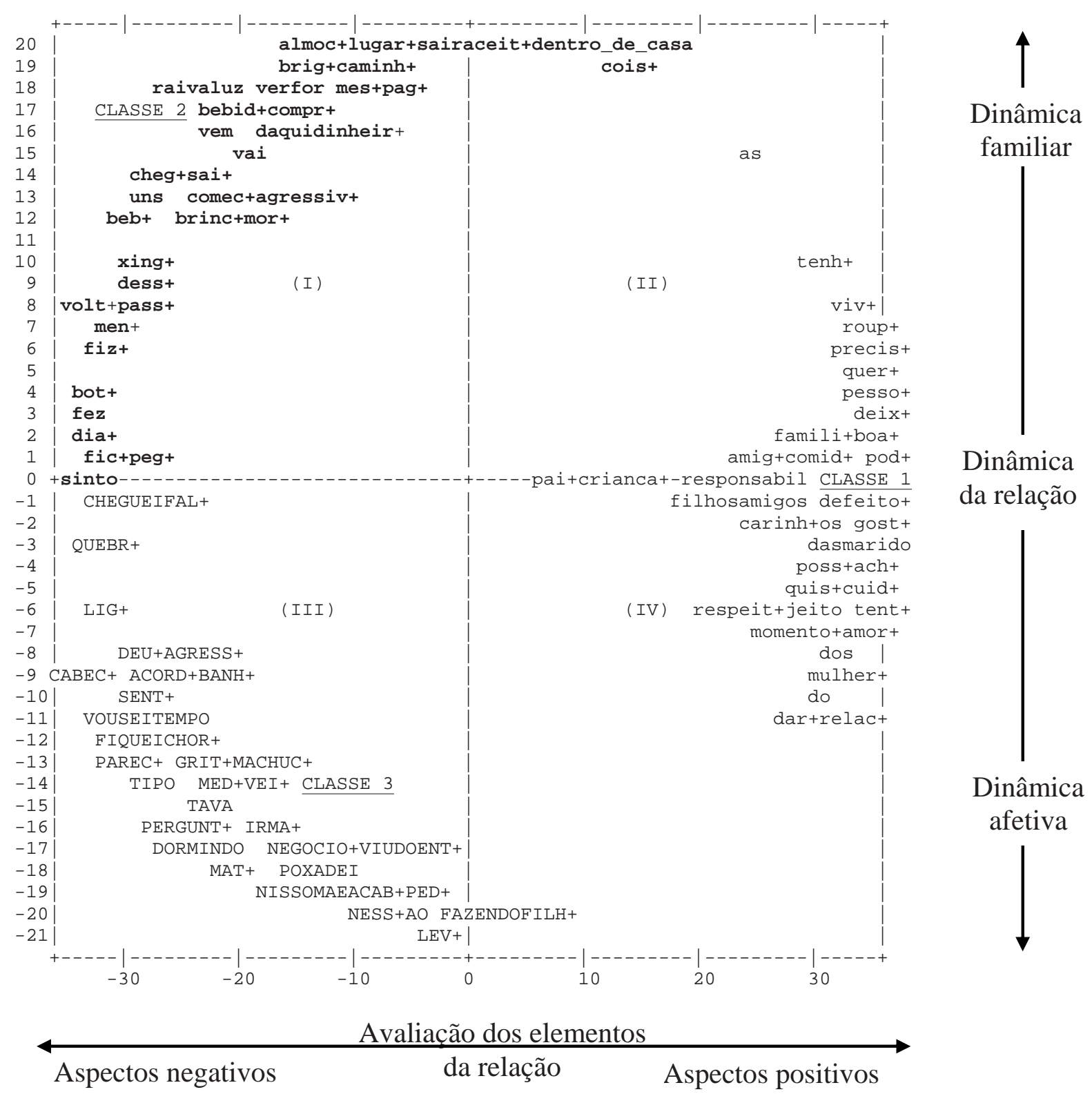

Figura 2. Representação gráfica da AFC do grupo de esposas - na posição (34,-1), considerando (x,y), estão sobrepostas as palavras: boa_esposa, dedic+, obrigaç+, boa_mãe, bom_marido, bom_pai, companheir+, dialog+, estud+, explic+, express+, meio, nel+, part+, relacionamen+, ruim, atenção, beij+, cama, divid+, important+, limp+, principal+. 
classe foram formatadas diferentemente. A observação inicial da figura nos permite situar as classes 1, 2 e 3, respectivamente entre os quadrantes II e IV, no quadrante I e no quadrante III. Uma primeira análise nos permite identificar as variáveis a que essas distribuições obedecem: no eixo horizontal (x) a organização das palavras obedece à avaliação (negativa ou positiva) dos elementos presentes no relacionamento; no eixo y, a posição das palavras varia de acordo com a qualidade da relação do casal: afetiva (troca de carinhos, atenção, diálogo...) ou familiar (tarefas e papéis domésticos: limpar, comida, prover/"não deixar faltar").

Na classe 1, Dinâmica Afetivo-familiar, são apresentados conteúdos unicamente positivos (concentrados à direita), distribuídos de forma bastante balanceada entre os quadrantes II e IV (dinâmica familiar e afetiva, respectivamente), o que reforça nossa compreensão de que, para as mulheres, a expressão de bons sentimentos e a execução das tarefas domésticas são características igualmente importantes para o bom funcionamento e harmonia da família e do casal.

Em oposição à classe 1, estão concentradas no lado esquerdo as classes 2 e 3 , as quais, pela CHD, encontram-se subagrupadas em um mesmo eixo, denominado Dinâmica $d a$ Violência. Temos então a classe 2, Insubordinação $e$ Conflitos, posicionada no primeiro quadrante e com as palavras concentradas mais consistentemente na parte superior do gráfico. O conteúdo predominante aqui são os aspectos negativos relativos às tarefas domésticas, principalmente descrições de brigas em função do descumprimento das tarefas de provedor pelo marido.

A classe 3, Violência e Frustração, localizada no terceiro quadrante, abaixo da classe 2, tem seu conteúdo disposto predominantemente na região inferior do gráfico. Os elementos afetivos negativos estão mais concentrados nessa classe, uma vez que aqui se destacam as descrições das agressões físicas e dos sentimentos (com relação ao parceiro e a seu relacionamento). Interessante notar a configuração dessas duas últimas classes, primeiramente pela posição oposta à primeira classe, por caracterizar um relacionamento com características incompatíveis com o ideal de família; em segundo lugar, pelo fato de seus conteúdos comporem um desenho que mostra a relação de continuidade entre elas, o que podemos entender como uma cadeia na qual os problemas com as obrigações domésticas ocasionam discussões e desentendimentos que podem gerar agressões psicológicas e físicas e o prejuízo das relações afetivas.

\section{Discussão}

Os dados obtidos com as mulheres participantes deste estudo possibilitam várias rotas interpretativas. Análises mais tradicionais, que tomam a mulher como uma vítima passiva da violência, poderiam interpretar os dados obtidos como evidências da subordinação das participantes aos interesses de seus companheiros, na medida em que suportaram a violência por vários anos. De fato, o que se observa aqui é que as relações com os companheiros são marcadas por forte ambigüidade, principalmente no que se refere às expectativas relacionadas ao "ser mulher" e "ser mãe".

Uma análise mais livre dos condicionamentos sociais, que procure ultrapassar a perspectiva da simples vitimização, permite identificar também a insubordinação nas ações dessas mulheres. Em primeiro lugar, é preciso relembrar que as participantes denunciaram oficialmente as violências sofridas e não retiraram a queixa. Salientamos que são diversas as barreiras enfrentadas ao longo da denúncia. Antes dessa, há a vergonha de assumir o papel de "mulher que apanha", o medo de "desestruturar a família" e mesmo a desaprovação por familiares e amigos próximos (Marques, 2005; Saffioti, 1999). O registro da denúncia é um momento à parte: mesmo as delegacias especializadas ainda não têm estrutura ou profissionais preparados para acolher essas mulheres, o que muitas vezes implica em um atendimento displicente e frio, quando não mal-orientado (Machado, 2002; Saffioti, 1999). Apesar de se ter constatado que, em um momento posterior à denúncia, pode haver redução das agressões físicas contra a mulher (Williams, 2001; Williams \& Pinheiros, 2006), não se tem dados específicos sobre alterações na freqüência e/ou intensidade da violência psicológica (ameaças à vida ou à integridade física, destruição de patrimônio, privação ou cerceamento de liberdade), violência essa aparentemente "mais sutil", mas que pode sinalizar que o bem-estar ou mesmo a vida da mulher ainda estão em risco.

Mesmo que nem todos esses aspectos sejam de conhecimento dessas mulheres, parece-nos que há, de fato, disposição para arriscar e buscar mudanças, o que demonstra, no mínimo, consciência de que estão rompendo limites significativos impostos pelos valores tradicionais e fazendo valer alguns de seus direitos, aí residindo o germe do empoderamento.

Em segundo lugar, os dados revelam que os conflitos conjugais são desencadeados pela desobediência das mulheres em relação a exigências dos companheiros, tanto relacionadas a "falhas" no seu desempenho como mulheres quanto como donas de casa, esposas ou mães. Com base nessa perspectiva, identificamos nos dados analisados um movimento que situa essas mulheres entre a conformação às expectativas tradicionais e o questionamento dessas mesmas expectativas. Pode-se dizer, então, que elas se encontram em um estado de tensão entre a subordinação a determinadas regras e a insubordinação em relação a diversas outras, como concepções sobre responsabilidades maternas, relacionamento conjugal e casamento.

Segundo Féres-Carneiro (1998, 2003) e Negreiros e Féres-Carneiro (2004), o casamento é, para a mulher, uma relação amorosa, enquanto para o homem este se refere à constituição de família. Os relatos das mulheres revelaram a coexistência e a complementação entre família e conjugalidade/relação afetiva, ambas importantes para a harmonia familiar. Destaca-se a necessidade da presença do homem como um parceiro nas decisões e cuidados com a casa, sendo, além de provedor e trabalhador, um homem companheiro, amigo e carinhoso com a esposa e os filhos, o que não se concretiza nos casos analisados.

Apesar de se mostrarem desiludidas com seus relacionamentos, as entrevistadas permaneciam casadas (Mara e seu parceiro moravam em casas separadas, mas continuavam se relacionando). Marques (2005) identificou em sua pesquisa alguns dos motivos alegados por mulheres para a manutenção da relação abusiva: amor pelo parceiro, esperança de ele mudar, cuidado com os filhos, questões econômicas, valores sociais (não querer ser mãe solteira), medo da violência e pena do parceiro, motivos também descritos por Barcellos (2003), Day e cols. (2003) e Saffioti (1999). Entre as participantes, 
apenas Mara declarou que, apesar das "coisas ruins", amava seu parceiro. Nos demais casos, a figura da mulher heroína/sofredora imperou em relação à da mulher infeliz, prevalecendo o sacrifício pelo bem-estar dos filhos e pelo bem maior que a instituição familiar representa. Nesse contexto, o padrão hegemônico de feminilidade foi reproduzido mais uma vez.

A questão da manutenção dos padrões tradicionais de gênero por meio da preservação de uma estrutura familiar patriarcal aparece como base importante para a compreensão dos conflitos domésticos e das agressões dos maridos contra suas esposas, uma vez que, no conteúdo analisado, predominam valores tradicionais relacionados aos papéis domésticos do homem e da mulher; o primeiro, provedor e protetor da família, e responsável principal pelo trabalho no espaço público, enquanto a segunda tem seu trabalho mais valorizado quando exercido no espaço privado (Boonzaier \& De la Rey, 2003; Rocha-Coutinho, 1994; Sarti, 2003). Por outro lado, a inserção dessas mulheres no mercado de trabalho destacou a necessidade de dividir e, ao mesmo tempo, delimitar funções para cada um dos cônjuges (Ridenti, 1998), o que revela um foco de tensões do desejo feminino, dada a dificuldade de se abrir mão de um dos poucos espaços de poder de que as mulheres dispõem. Como concluiu Rocha-Coutinho (2003), "a mulher de hoje apenas multiplicou funções, mas ainda não dividiu responsabilidades" (p. 17, grifos nossos). Desse modo, identificamos nas entrevistadas mulheres que buscam ocupar novos espaços públicos, além de manter alguns de seus papéis privados tradicionais.

Um elemento menos tradicional apareceu nas concepções acerca do "novo pai”, embora ainda não esteja, de fato, integrado às práticas: a paternidade passa a incorporar compromissos com alimentação e saúde e, também, envolvimento afetivo na criação dos filhos. Estudos sobre representações e vivências da paternidade indicam que o envolvimento afetivo paterno tem se restringido às brincadeiras e atividades de lazer, reservando-se ainda às mulheres todos os outros cuidados (Trindade, Andrade \& Souza, 1997; Trindade \& Menandro, 2002)

Além disso, identificamos elementos indicativos de que as mulheres buscam alterar suas posições perante as situações e perspectivas de vida impostas a elas, a saber: 1) Descontentamento e exigências com relação ao papel desempenhado pelo marido como chefe da família: as entrevistadas cobram maior envolvimento dos maridos nas suas obrigações com a família; 2) Realização de trabalho remunerado por todas as mulheres. Vale ressaltar que em um caso a esposa era a principal provedora da casa; 3) Reapropriação dos direitos sobre seus corpos, evidenciada pela necessidade de contato com o mundo público (trabalho, amigos), cuidados pessoais e estéticos e questionamentos acerca de sua vida sexual.

Se algumas dessas ações podem parecer demasiadamente sutis no contexto mais amplo da luta coletiva (como insistir em usar uma roupa que o marido não quer), no contexto analisado, elas configuram um movimento de autonomia promovido individualmente por essas mulheres: ao invés de uma postura derrotista diante dos sofrimentos e do descontentamento com suas vidas e seus relacionamentos, elas, por meio de posturas ativas (trabalho remunerado, exigências/cobranças feitas ao marido, domínio do próprio corpo), enfrentam seus maridos na busca de condições e qualidade de vida melhores para elas e sua família. A transformação dessas mulheres em membros ativos da família, para além dos cuidados domésticos, pode ter consequiências positivas também para o homem, por exemplo, ao reinseri-lo no contexto familiar como figura afetiva (Trindade \& cols., 1997; Trindade \& Menandro, 2002), mas parece ser, principalmente, um fator implicado nas ocorrências de conflitos e brigas entre os casais.

Considerando, como Dantas-Berger e Giffin (2005) e Giffin (2002), que estamos diante de uma "transição de gênero", devemos ponderar os ganhos da "nova mulher" (direitos reprodutivos, aumento na participação no orçamento familiar), as repercussões negativas desses avanços (aprofundamento da dupla jornada, reprodução da desigualdade de gênero e classe), e o que as autoras denominam descompasso do "tempo de gênero" (Dantas-Berger \& Giffin, 2005, p. 419) masculino, fatores que podem estar potencializando/produzindo conflitos nas relações de gênero. Ainda, avaliamos que tal descompasso está relacionado à busca de mudança pelas mulheres em situação de reconhecida subordinação, enquanto os homens tentam mantê-la (Connell, 1995; Greig \& cols., 2000).

Essa transformação ameaça então, os limites entre o que nossa sociedade compreende como feminino e masculino, uma vez que implica a entrada da mulher no espaço público, como produtora, e na necessidade de o homem reestruturar seu papel, na busca de outros meios para fortalecimento de sua masculinidade. Segundo Nolasco (1997, p. 26), "há na relação homem e mulher uma expectativa de que o homem domine essa relação". Nesse sentido, o uso de violência pelo parceiro aparece como forma de reafirmar sua identidade masculina, pois a agressividade ainda é culturalmente associada ao masculino e, por conseqüência, um meio de se fazer e se mostrar diferente da mulher. Um exemplo fornecido pelas próprias entrevistadas, e que ilustra essa questão, é a reapropriação de seus corpos: ao mesmo tempo em que expõe uma conquista relacionada à autonomia, o domínio do próprio corpo ameaça a segurança da mulher posto que intimida a autoridade masculina na relação conjugal. A reação masculina a essa ameaça aparece, então, nas agressões físicas ou verbais e, em último caso, na sujeição do corpo da mulher como meio "simbólico de recolocá-la no lugar hierarquicamente subordinado de esposa" (Cavalcanti, Gomes \& Minayo, 2006, p. 34).

Acreditamos que a transição de gênero está relacionada ao processo de empoderamento das mulheres iniciado pelos movimentos feministas, os quais, nos tempos atuais, têm apresentado efeitos mais visíveis, ainda que pouco satisfatórios, no cotidiano das mulheres e das organizações familiares. Ao discutir o empoderamento das mulheres, Kabeer (2005) definiu inicialmente o desempoderamento como a negação da possibilidade de escolha. Dessa forma, o empoderamento se refere ao processo pelo qual aqueles a quem se negou a habilidade de escolha adquirem tal habilidade. Além disso, a autora ressalta as dificuldades existentes no processo de empoderamento, ao apontar que esse implica no desafio das relações de poder estabelecidas, sem violar a capacidade de escolha do outro, e que condições como educação, acesso a trabalho remunerado e representação política têm sim efeitos positivos no processo de empoderamento.

Ainda, devemos atentar não apenas para essas questões individuais, embora sejam, de fato, significativas na vida de cada uma dessas mulheres. Como observou León (2001), o 
empoderamento relacionado ao aumento da auto-estima e autonomia deve ser integrado a um processo comunitário de cooperação e solidariedade ou poderá não passar de uma situação ilusória. Nesse sentido, devemos destacar que as mudanças femininas identificadas são individuais, na medida em que não verificamos nas entrevistas relatos sobre mobilizações ou grupos comunitários que discutem alternativas de organização dos papéis de gênero, fora do padrão hierárquico hegemônico. Essas reações pessoais, porém, não são individualistas, pois devem ser compreendidas dentro de um contexto social que possibilita à mulher o acesso a temas e discussões referentes às lutas e conquistas sociais femininas (meios de comunicação de massa, propagandas e novelas, trocas de experiências pessoais entre conhecidas), fortalecendo, assim, a imagem da "nova mulher". Por essa razão, podemos compreender que as atitudes reativas das mulheres são expressão de um processo de empoderamento. Processo, por não ser uma situação acabada, mas que reflete a busca por serem reconhecidas como mulheres de direito, que merecem ser ouvidas e respeitadas em suas escolhas.

A ausência de uma estrutura que ofereça à mulher e ao homem o espaço para discussões e reelaborações de suas concepções e relações de gênero fragiliza os movimentos femininos individuais e possibilita uma reação dos homens que, excluídos e desinteressados das discussões acerca do empoderamento feminino, tendem a compreender esse processo como "desempoderamento masculino" ou perda da posição de dominação legitimada pelo patriarcado (León, 2001). Nesses termos, compreendemos a reação violenta do marido como uma tentativa de reaver/manter o controle sobre sua esposa e, assim, resistir à transição de gênero (Dantas-Berger \& Giffin, 2005). O acesso e uso do poder pelas mulheres representam, assim, um desafio às relações patriarcais, principalmente no ambiente familiar, uma vez que desafiam o poder do homem e ameaçam seus privilégios, sinalizando a possibilidade de mudança na relação de dominação dos homens sobre as mulheres. Alteração essa que proporciona às mulheres a autonomia sobre seus corpos, sua sexualidade e seu direito de ir e vir e também o repúdio ao abuso físico, à impunidade e às decisões unilaterais masculinas.

\section{Referências}

Alvim, S. F. \& Souza, L. (2005). Violência conjugal em uma perspectiva relacional: homens e mulheres agredidos/agressores. Psicologia: Teoria e Prática, 7(2), 171-206.

Anderson, K. L \& Umberson, D. (2001). Gendering violence: masculinity and power in men's accounts of domestic violence. Gender \& Society, 15(3), 358-380.

Araújo, M. F. (2005). Diferença e igualdade nas relações de gênero: revisando o debate. Psicologia Clínica, 172(2), 41-52.

Barcellos, G. H. (2003). Atuação das delegacias especializadas da mulher no estado do Espírito Santo. Em T. Camacho (Org.), Ensaios sobre Violência (pp. 115-167). Vitória: Edufes.

Bardin, L. (2002). Análise de Conteúdo. (L. A. Reto \& A. Pinheiro, Trads.). Lisboa: Edições 70. (Trabalho original publicado em 1977)

Boonzaier, F. \& De la Rey, C. (2003). "He's a Man, and I'm a woman"- cultural constructions of masculinity and femininity in South African women's narratives of violence. Violence against Women, 9(8), 1003-1029.
Bourdieu, P. (2003). A dominação masculina (M. H. Kühner, Trad.) ( $3^{\mathrm{a}}$ ed.). Rio de Janeiro: Bertrand Brasil.

Bruschi, A., de Paula, C. S. \& Bordin, I. A. S. (2006). Prevalência e procura de ajuda conjugal física ao longo da vida. Revista de Saúde Pública, 40(2), 256-264.

Cavalcanti, L. F., Gomes, R. \& Minayo, M. C. S (2006). Representações sociais de profissionais de saúde sobre violência sexual contra a mulher: estudo em três maternidades públicas municipais do Rio de Janeiro, Brasil. Cadernos de Saúde Pública, 22(1), 31-39.

Chauí, M. (1999, 13 de março). Uma ideologia perversa. Folha de São Paulo, Caderno Mais, p. 5.

Connell, R. W. (1995). Masculinities. Cambridge: Polity.

Connell, R. W. (2005). Hegemonic masculinity - rethinking the concept. Gender \& Society, 19(6), 829-859.

Cortez, M.B., Padovani, R. C. \& Williams, L. C. A. (2005). Terapia de grupo cognitivo-comportamental com agressores conjugais. Estudos de Psicologia, 22(1), 13-21.

Dantas-Berger, S. M. \& Giffin, K. (2005). A violência nas relações de conjugalidade: invisibilidade e banalização da violência sexual? Cadernos de Saúde Pública, 21(2), 417-425.

Dasgupta, S. (2002). A Framework for understanding women's use of nonlethal violence in intimate heterosexual relationships. Violence against Women, 8(11), 1364-1389.

Day, V. P., Telles, L. E. B., Zoratto, P. H., Azambuja, M. R. F., Machado, D. A., Silveira, M. B. \& cols. (2003). Violência Doméstica e suas diferentes manifestações. Revista de Psiquiatria do Rio Grande do Sul, 25(Suplemento 1), 9-21.

Dutton, D. G. \& Nicholls, T. L. (2005). The gender paradigm in domestic violence research and theory: Part 1-The conflict of theory and data. Aggression and Violent Behavior, 10, 680-714.

Féres-Carneiro, T. (1998). Casamento contemporâneo: o difícil convívio da individualidade com a conjugalidade. Psicologia: Reflexão e Crítica, 11(2), 379-394.

Féres-Carneiro, T. (2003). Separação: o doloroso processo de dissolução da conjugalidade. Estudos de Psicologia, 8(3), 367-374.

Giffin, K. (1994). Violência de gênero, sexualidade e saúde. Cadernos de Saúde Pública, 10(suplemento 1), 146-155.

Giffin, K. (2002). Pobreza, desigualdade e eqüidade em saúde: considerações a partir de uma perspectiva de gênero transversal. Cadernos de Saúde Pública, 18(Suplemento), 103-1125.

Gilbert, P. R. (2002). Discourses of female violence and societal gender stereotypes. Violence against women, 8(11), 1271-1300.

Greig, A., Kimmel, M. \& Lang, J. (2000). Men, masculinities \& development: Broadening our work towards gender equality. Gender in Development Programme, UNDP: Gender in Development Monograph Series \#10. Retirado em 10/07/2005 do site http://health.columbia.edu/pdfs/men_masculinities.pdf

Jenkins, S. S. \& Aubé, J. (2002). Gender differences and genderrelated constructs in dating aggression. Personality and Social Psychology Bulletin, 28(8), 1106-1118.

Kabeer, N. (2005). Gender equality and women's empowerment: a critical analysis of the third Millennium Development Goal. Gender and Development, 13(1), 13-24.

Kelly, V. A. (2004). Psychological abuse of women: a review of the literature. The family journal: counseling and therapy for couples and families, 12(4), 383-388

León, M. (2001). El empoderamiento de las mujeres: encuentro del primer y tercer mundos em los estudios de género. La ventana, (13), 94-106. Retirado em 03/07/2005 do site http://publicaciones. cucsh.udg.mx/pperiod/laventana/Ventana13/vetana13-4.pdf 
Machado, L. Z. (2002). Atender vítimas, criminalizar violências. Dilemas das delegacias da mulher. Série Antropologia, 319. Brasília.

Marcondes Filho, C. (2001). Violência fundadora e violência reativa na cultura brasileira. São Paulo em Perspectiva, 15(2), 20-27.

Marques, T. M. (2005). Violência conjugal: estudo sobre a permanência da mulher em relacionamentos abusivos. Dissertação de Mestrado, Universidade Federal de Uberlândia, Uberlândia.

Menandro, M. C. S. (2004). Gente jovem reunida: um estudo de representações sociais da adolescência/juventude a partir de textos jornalísticos (1968/1974 e 1996/2002). Tese de Doutorado, Universidade Federal do Espírito Santo, Vitória.

Miller, L. (2002). Protegendo as mulheres da violência doméstica. Em L. Q. Moraes \& R. Naves (Orgs.), Advocacia pro bono em defesa da mulher vítima de violência (pp. 223-263). Campinas: Unicamp.

Minayo, M. C. S. (1993). O desafio do conhecimento - pesquisa qualitativa em saúde. São Paulo: Hucitec/Abrasco.

Negreiros, T. C. G. M. \& Féres-Carneiro, T. (2004). Masculino e feminino na família contemporânea. Estudos e Pesquisas em Psicologia, 4(1), 34-47.

Nolasco, S. (1997). Um "homem de verdade”. Em D. Caldas (Org.), Homens (pp. 13-29). São Paulo: Senac.

Oliveira, D. C., Gomes, A. M. T. \& Marques, S. C. (2005). Análise estatística de dados textuais na pesquisa das representações sociais: alguns princípios e uma aplicação ao campo da saúde. Em M. S. S. Menin \& A. M. Shimizu (Orgs.), Experiência e representação social: questões teóricas e metodológicas (pp. 157-200). São Paulo: Casa do Psicólogo.

Pondaag, M. C. M. (2003). O dito pelo não dito: desafio no trabalho com mulheres vítimas de violência. Dissertação de Mestrado, Universidade de Brasília, Brasília.

Ribeiro, A. S. M. (2000). Macho, adulto, branco, sempre no comando? Dissertação de Mestrado, Universidade de Brasília, Brasília.

Ridenti, S. G. U. (1998). A desigualdade de gênero nas relações parentais: O exemplo da custódia dos filhos. Em M. Arilha, S. G. U. Ridenti, \& B. Medrado (Orgs.), Homens e masculinidades: outras palavras (pp. 163-184). São Paulo: Ecos/Ed 34.

Rocha-Coutinho, M. L. (1994). Tecendo por trás dos panos: a mulher brasileira nas relações familiares. Rio de Janeiro: Rocco.
Rocha-Coutinho, M. L. (2003). Novas opções, antigos dilemas: mulher, família, carreira e relacionamento no Brasil. Temas em Psicologia da SBP, 11(1), 2-17.

Saffioti, H. I. B. (1999). Já se mete a colher em briga de marido e mulher. São Paulo em Perspectiva, 13(4), 82-91.

Saffioti, H. I. B. (2002). Contribuições feministas para o estudo da violência de gênero. Em L. Q. Moraes \& R. Naves (Orgs.), Advocacia pro bono em defesa da mulher vítima de violência (pp. 197-221). Campinas: Unicamp.

Saffioti, H. I. B. \& Almeida, S. S. (2003). Brasil: violência, poder e impunidade. Em T. Camacho (Org.). Ensaios sobre violência (pp. 85-114). Vitória: Edufes

Sarti, C. A. (2003). A família como espelho: um estudo sobre a moral dos pobres. ( $\left.2^{\mathrm{a}} \mathrm{ed}\right)$. São Paulo: Cortez.

Soares, B. M. (1999). Mulheres invisíveis: violência conjugal e novas políticas de segurança. Rio de Janeiro: Civilização Brasileira.

Torrão Filho, A. (2005). Uma questão de gênero: onde o masculino e o feminino se cruzam. Cadernos Pagu, (24), 127-152.

Trindade, Z. A., Andrade, C. A. \& Souza, J. Q. (1997). Papéis parentais e representações da paternidade: a perspectiva do pai. Psico, 28(1), 207-222.

Trindade, Z. A. \& Menandro, M. C. S. (2002). Pais adolescentes: vivência e significação. Estudos de Psicologia, 7(1), 15-23.

Williams, L. C. A. (2001). The impact of reporting violence at a Brazilian Women's Police Station on female self-report of partner fisical agression. Em: Resumos do VI International Conference on Family Violence, San Diego-California; p. 1-13.

Williams, L. C. A. \& Pinheiro, F. M. F. (2006). Efeitos da denúncia da mulher na reincidência da violência física do parceiro. Revista Brasileira de Ciências Criminais, 14(63), 309-332.

Wood, J. T. (2004). Monsters and victims: male felon's accounts of intimate partner violence. Journal of Social and Personal Relationships, 21(55), 555-576.

Recebido em 22.12.2006

Primeira decisão editorial em 05.06.2007

Versão final em 18.02.2008

Aceito em 23.03.2008 